Authors' reply: We are grateful for the opportunity to respond to Dr Calton. He challenges claims for objectivity in the diagnosis of any disorder that has an interpersonal component, taking as his example some research into the diagnosis of personality disorder. He queries why we do not consider the role of the therapist's personality in our paper, 'Objectivity in psychoanalytic assessment of couple relationships' (Lanman et al, 2003). In that paper, where we show evidence of a good degree of objectivity (based on interrater reliability) for the diagnoses we discuss, we specifically refer to the fact that those making the judgements need to have had a psychoanalytically based training in order to develop their ability to make use of their emotional reactions to the patient.

Our paper deals with psychotherapeutic diagnoses, rather than with psychiatric ones, but on the basis of our work we would like to comment on Dr Calton's position. First, there are likely to be very significant differences in what is judged to be a helpful 'fit' between therapist and patient, between the two different domains of general psychiatry and psychoanalytic psychotherapy. In the former, a friendly and sympathetic stance may be the crucial therapeutic vehicle for providing medication and other treatments. But in the domain of psychotherapy it is not necessarily a good thing to 'match' therapist to patient, if by this one means attempting to avoid prejudices or sensitive areas, because this is likely to lead to a serious evasion of the darker areas of interaction, conscious and unconscious, where the significant problems will tend to lie. If the study of the interaction 'in the room', between therapist and patient, is itself the treatment, then the therapist's best equipment for this is self-knowledge, including knowledge of the darker areas of his or her own personality and knowledge of how to recognise and use the ways in which these affect him or her.

While personal psychotherapy together with detailed supervision by no means guarantee the development of such knowledge and there will be practitioners who are unable to respond, as well as therapies which do not go far enough - these remain the best available means of acquiring the skills necessary to work with unconscious processes, enabling a therapist to understand a patient's personality difficulties of and the way these interact with their own. Outside this particular field, it may not be widely recognised that one of the principal tools of contemporary psychoanalytic therapy is the constant monitoring by practitioners of their own emotional responses to patients, not simply in order to suppress or redirect them, but in order to gain information that the therapist will then be able to employ in clinical diagnosis and engagement with patients. This is not to be confused with the self-disclosure advocated by some therapies. In our view there is no substitute for a rigorous psychotherapeutic training in this area, which includes selection of trainees, personal psychotherapy and detailed supervision.

Lanman, M., Grier, F. \& Evans, C. (2003) Objectivity in psychoanalytic assessment of couple relationships. British Journal of Psychiatry, I82, 255-260.

F. Grier, M. Lanman, C. Evans Tavistock Menta Studies Institute, The Tavistock Centre, 120 Belsize Lane, London NW3 5BA, UK

\section{Creativity and mental health}

After thoroughly enjoying Dr Wills' 1988 book (Wills \& Cooper, 1988) I was dismayed to see his recent article (Wills, 2003). His book detailed the real, unremitting and often unique stressors faced by those struggling to make a living from music - as opposed to the pop-psychology focus on their (allegedly) inherent psychological flaws.

Although entertaining, psychological autopsies are not valid research tools, as the author fortunately points out in the 'limitations' box. Further, the 'comprehensive literature' about the psychopathology/ creativity link is shot through with badly designed studies and dramatic overstatement.

Like Wills, Jamison (1989) was the sole judge of her hand-picked sample - 47 creative artists - but few authors dig up her unreplicated original work, preferring to pass along her unscientific conclusions. For example, many introductory psychology textbooks include her contention that $50 \%$ of poets have affective disorders, without noting that she had only 18 poets in her sample and moreover diagnosed affective disorder as simply 'seeking treatment' for it. And while Ludwig's book (1995) is full of charts and graphs, on close and trained inspection they are overwhelmingly meaningless; despite its subtitle, it actually resolves nothing at all.

Unfortunately, the tradition in this field is to pass along any confirmatory 'mad creative' conclusions, regardless of any liberties taken with the scientific method.
Most of the common research blunders are detailed by Arnold Rothenberg (1990), as well as in my own work (Schlesinger, $2002 a, b)$. Such flaws should have been fatal, but apparently the public appetite for the doomed artist is too great. It's a shame that so many professionals continue to feed it with their invalid speculation. As Wills understands better than most, musicians don't need anything else to worry about.

Jamison, K. R. (1989) Mood disorders and patterns of creativity in British writers and artists. Psychiatry, $\mathbf{5 2}$ 125-134.

Ludwig, A. M. (1995) The Price of Greatness: Resolving the Creativity and Madness Controversy. New York: Guilford Press.

Rothenberg, A. (1990) Creativity and Madness: New Findings and Old Stereotypes. Baltimore, MD: Johns Hopkins University Press.

Schlesinger, J. (2002a) Issues in creativity and madness: part one, ancient questions and modern answers. Ethical Human Sciences and Services: An International Journal of Critical Inquiry, 4, 73-76.

Schlesinger, J. (2002b) Issues in creativity and madness: part two, eternal flames. Ethical Human Sciences and Services: An International Journal of Critical Inquiry, 4 . 139-142.

Wills, G. \& Cooper, C. L. (1988) Pressure Sensitive: Popular Musicians under Stress. London: Sage.

Wills, G. (2003) Forty lives in the bebop business: mental health in a group of eminent jazz musicians. British Journal of Psychiatry, 183, 255-259.

J. Schlesinger 300 Broadway, Suite 3B, Dobbs Ferry, New York 10522, USA

Author's reply: Schlesinger feels that 'psychological autopsies are not valid research tools', and is scathingly critical of the work of Jamison (1989) and Ludwig (1995). However, she fails to take into account the conclusions of Jamison's later work (1993), which, as well as reporting on her own study of 47 contemporary British writers and artists, also discusses biographical material relating to 195 famous artistic creative persons, $21.5 \%$ of whom died by suicide and $33.3 \%$ of whom were hospitalised with psychiatric problems. Jamison also refers to many academic studies of creativity and mental illness stretching back over the past century.

Turning to what Schlesinger describes as Ludwig's 'overwhelmingly meaningless' charts and graphs, I have to say that I find his statistics perfectly acceptable and meaningful. The use of psychological autopsies is a legitimate exercise if one follows rigorous 
guidelines as laid down, for instance, in the scholarly work of Runyan (1982).

What is Schlesinger's own view of the creative person? She tells us (2002) that he/she is a heroic and mystical figure, branded as mad by the jealous and uncomprehending average person. This is a straightforward reiteration of the ideas of the antipsychiatry movement of the 1960s and 1970s. We are back in the realms of the Laingian figure who is simply too insightful and too existentially aware for our society. Have we not moved on since then?

Jamison, K. R. (1989) Mood disorders and patterns of creativity in British writers and artists. Psychiatry, $\mathbf{5 2}$ 125-134.

Jamison, K. R. (1993) Touched With Fire: Manic Depressive Illness and the Artistic Temperament. New York: Free Press.

Ludwig, A. M. (1995) The Price of Greatness: Resolving the Creativity and Madness Controversy. New York: Guilford Press.

Runyan, W. M. (1982) Life Histories and Psychobiography: Explorations in Theory and Method. New York: Oxford University Press.

Schlesinger, J. (2002) Issues in creativity and madness. Part two: eternal flames. Ethical Human Sciences and Services: An International Journal of Critical Inquiry. 4, 139-142.

G.Wills 13 Mile End Lane, Davenport, Stockport, Cheshire SK2 6BN, UK

\section{Creativity, mental disorder and jazz}

I am very happy that Poole (2003) feels that my paper (Wills, 2003) makes a significant contribution to the literature on the relationship between creativity and mental disorder. Nevertheless, I would like to comment on certain points that he makes.

First, the literature on the above topic may be flawed, but it is not small, since an abundance of references extends back at least a hundred years, and it is not inconclusive, since a regular finding is that of the connection between high artistic creativity and mood disorders.

Second, although jazz biographies are written in order to sell books, they tend to be sober, respectful and well-researched, and often are written by academics. Even the most comprehensive psychiatric assessment cannot match the time and effort expended by responsible biographers.

Poole feels that I was uncritical in my acceptance that Thelonious Monk had a dementing process caused by excessive drug usage. My information was taken from the biography by Gourse (1997).
She interviewed Dr Everett Dulit, a Monk afficionado who discussed Monk's case with doctors who knew him, and who felt that drug-induced dementia was the likely diagnosis. Similarly, Poole feels that John Coltrane did not necessarily exhibit pathological behaviours, yet first-person accounts in six Coltrane biographies describe these, and in his acclaimed biography Porter (1998) states, 'There is absolute agreement that Coltrane practiced maniacally....

Poole's belief that 'Even severe mental disorder is not incompatible with creativity...there is no negative association between the two' needs clarification. It depends on the type, and the stage of development of the mental disorder. For instance, hypomania often facilitates creativity, but severe depression will extinguish it (Akiskal \& Akiskal, 1988).

A better understanding of the link between creativity and mental disorder will help great artists to do what they do best - be creative.

Akiskal, H. S. \& Akiskal, K. (1988) Reassessing the prevalence of bipolar disorders: clinical significance and artistic creativity. Psychiatry and Psychobiology, 3 (suppl.) $29 s-36 s$

Gourse, L. (1997) Straight, No Chaser: The Life and Genius of Thelonious Monk. New York: Schirmer.

Poole, R. (2003) 'Kind of Blue': creativity, mental disorder and jazz. British Journal of Psychiatry, I83, 193-194.

Porter, L. (1998) John Coltrane: His Life and Work. Ann Arbor, MT: University of Michigan Press.

Wills, G. (2003) Forty lives in the bebop business: mental health in a group of eminent jazz musicians. British Journal of Psychiatry, 183, 255-259.

G.Wills 13 Mile End Lane, Davenport, Stockport Cheshire SK2 6BN, UK

\section{Flashbacks in war veterans}

Jones et al (2003b) appears to have missed the point of my letter (Burges Watson, 2003). They define flashbacks as 'a form of dissociative state' (Jones et al, 2003a). This is the way the term flashback is used in the DSM-IV; 'dissociative flashback episodes' (American Psychiatric Association, 1994). They appear as an example of one of five ways in which 'the traumatic event is persistently re-experienced'. Only one is necessary for the diagnosis. As such they are not 'a core symptom' of post-traumatic stress disorder. As defined in DSM-IV, flashbacks themselves are no more than 'a recurrence of a memory, feeling or perceptual experience from the past'. This definition may well have been introduced because of the popularity of the term 'flashback' and necessary because its original meaning had been changed by popular usage. Jones et al are probably right when they hypothesise that this popularity was encouraged by the use of flashbacks in films and television programmes.

The changing presentation of symptoms associated with the extreme stress of war is indeed interesting. Bizarre dissociative states with physical manifestations, while very common in the First World War, were comparatively rare in the Second World War and very uncommon in Vietnam veterans. Thus, in line with the focus on physical symptoms in earlier wars, it would seem that the presentation of dissociative states has also moved from the physical to the psychological.

American Psychiatric Association (1994) Diagnostic and Statistical Manual of Mental Disorders (4th edn) (DSM-IV). Washington, DC: APA.

Burges Watson, I. P. (2003) Flashbacks and PTSD (letter). British Journal of Psychiatry, 183, 75-76.

Jones, E., Vermaas, R. H., McCartney, H., et al (2003a) Flashbacks and post-traumatic stress disorder: the genesis of a 20th-century diagnosis. British Journal of Psychiatry, 182, 158-163.

Jones, E., Vermaas, R. H., Beech, C., et al (2003b) Flashbacks and PTSD: authors' reply (letter). British Journal of Psychiatry, 183, 76-77.

I. P. Burges Watson The Hobart Clinic, Rokeby, Tasmania, Australia 7019

\section{Mental health and social capitals}

The correspondence prompted by McKenzie et al's (2002) editorial suggests that social capital can be the property of individuals as well as groups (Pevalin, 2003; Walkup, 2003). However, McKenzie finds this idea problematic and argues that, as the majority of health scientists conceive of social capital as an ecological concept, we should 'consider effects at an individual level as social networks' (McKenzie, 2003: p. 458). This restricted view rejects the potential contribution to psychiatric research of alternative sociological conceptions of social capital that are both rigorously defined and empirically tested.

One such approach is taken by Lin et al (2001) who adopt neo-Marxist notions of capital. Here, social capital is 'investment in social relations by individuals through which they gain access to embedded resources to enhance expected returns of 